\title{
$\mathrm{Cr}_{1-\mathrm{x}} \mathrm{Mo}_{\mathbf{x}} \mathrm{B}_{2}$ 系セラミックスの焼結
}

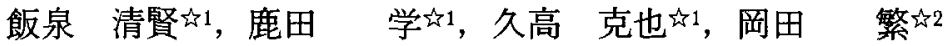 \\ 的 1 東京工芸大学工学部工業化学科, $\mathbf{T} 243-02$ 厚木市飯山1583. 保 2 神奈川大学工学部応用化学科, \\ 于221 横浜市神奈川区六角橋3-27-1.
}

\section{Sintering of $\mathrm{Cr}_{1-\mathrm{x}} \mathrm{Mo}_{\mathbf{x}} \mathrm{B}_{2}$ Ceramics}

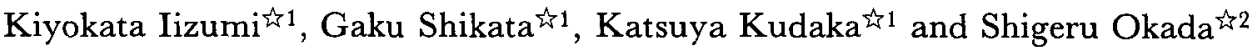

if Department of Industrial Chemistry, Faculty of Engineering, Tokyo Institute of Polytechnics, 1583 Iiyama, Atsugi 243-02. Department of Applied Chemistry, Faculty of Engineering, Kanagawa University, Rokkakubashi Kanagawa-ku, Yokohama 221.
\end{abstract}

Received December 16, 1996

\section{SYNOPSIS}

$\mathrm{Cr}_{1-\mathbf{x}} \mathrm{MO}_{\mathbf{x}} \mathrm{B}_{2}$ ceramics were manufactured by hot-pressing at the temperatures between 1600 and $1900^{\circ} \mathrm{C} . \mathrm{CrB}_{2}$, Mo and amorphous boron powders were mixed in selected ratios. The ceramics were characterized by lattice constants, density and hardness.

The X-ray diffraction data showed that the molybdenum solubility $x$ into the ceramics is about 0.6 at the temperatures of $1600-1800^{\circ} \mathrm{C}$ and increases to about 0.8 at $1900^{\circ} \mathrm{C}$. Apparent density of the ceramics increased as molybdenum content and hot-pressing temperature increased. SEM observations showed that boride grains in the ceramics grows rapidly over the hot-pressing temperature of $1800{ }^{\circ} \mathrm{C}$. Vickers hardness of the ceramics is a function of hot-pressing temperature and molybdenum content, and reached maximum value of $26.5 \mathrm{GPa}$ at $1700^{\circ} \mathrm{C}$ and $\mathrm{x}=0.6$.

\section{KEY WORDS}

$\mathrm{Cr}_{1-\mathrm{x}} \mathrm{MO}_{\mathbf{x}} \mathrm{B}_{2}$ ceramics, hot press, hardness, solid solution

\section{1 緒 言}

クロムホウ化物は一般に高融点, 高硬度,電気伝導 性を有する化合物であり, o- $\mathrm{Cr}_{2} \mathrm{~B}, \mathrm{t}-\mathrm{Cr}_{2} \mathrm{~B}, \mathrm{Cr}_{5} \mathrm{~B} 3, \mathrm{CrB}$, $\mathrm{Cr}_{2} \mathrm{~B}_{3}, \mathrm{Cr}_{3} \mathrm{~B}_{4}, \mathrm{CrB}_{2}$ および $\mathrm{CrB}_{4}$ の八種類の化合物が報

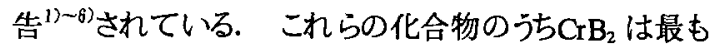
高融点 $\left(2200^{\circ} \mathrm{C}\right)$, 高硬度 $(20.5 \mathrm{GPa})^{2)}$ を有する化合物 であり, 高温強度材料, 而摩耗材料しして有望視されて いる. また一方 $\mathrm{MoB}_{2}$ (六方晶系)は融点 $2350^{\circ} \mathrm{C}$, 硬
さ11.8 $\mathrm{GPa}^{2}$ をもつ化合物である. 従って,これらの化 合物は単体では高融点のため難焼結性であるが,これ らの化合物間の固溶体を作製することにより焼結性を促 進させ,さらに高強度, 高硬度の複合セラミックスが得ら れることが期待される.

本研究では $\mathrm{CrB}_{2}-\mathrm{MoB}_{2}$ 系複合セラミックスの焼結性, 機械的性質などの向上を目的しして, $1400^{\circ} \mathrm{C} て ゙ の C r-$ Mo-B三元系平衡状態図 ${ }^{7)}$ に基づいてセラミックスの組 
成を $\mathrm{Cr}_{1-\mathrm{x}} \mathrm{Mox}_{2} \mathrm{~B}_{2}$ しし， $\mathrm{x}=0.2 \sim 0.80$ 範囲で $\mathrm{x}$ (モりブデ ン量)を選んで実験を行った， $\mathrm{Cr}_{1 \times} \times \mathrm{Mo}_{\mathrm{x}} \mathrm{B}_{2}$ 系セラシック スのホットプス焼結を行い, 焼結体の格子定数, 密度 および硬さを測定し，焼結体の硬さに及ぼすモリブデン

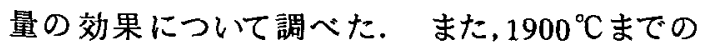
$\mathrm{Cr}_{1-\mathrm{x}} \mathrm{Mo}_{\mathrm{X}} \mathrm{B}_{2}$ 系セラミックスのホットプレス焼結を行い,格 子定数の変化からモリブデンの固溶限界につて検討 した.

\section{2 実験方法}

出発原料は $\mathrm{CrB}_{2}$ (日本新金属社製, 平均粒径 5.4 $\mu \mathrm{m})$ 粉末，モリブデン（日本新金属社製，平均粒径. $0.6 \mu$ m) 粉末および非晶質ホウ素(Hermann. C.

Starck 社製, 平均粒径 $0.8 \mu \mathrm{m})$ 粉末を使用した。試料 の組成を $\mathrm{Cr}_{1-\mathrm{x}} \mathrm{Mox}_{\mathrm{x}} \mathrm{B}_{2}(\mathrm{x}=0.2 \sim 0.8)$ 乙して, 所定の割合 に配合した原料粉末を，遊星型ボールミルフフリッュ・ジャ パン(株))を使用して、それぞれ1時間混合粉砕した

これらの混合粉末を黒鉛製多イスに充填し，真空中 $(x$ $10^{-3} \mathrm{~Pa}$ ), 压力約 $40 \mathrm{MPa}, 1600 \sim 1900^{\circ} \mathrm{C}$ でれぞれ 1 時間ホットプレスを行った

得られた焼結体は表面を研磨した後,水銀置換法に より見かけ密度の測定を行い,ヴィッカース硬度計((株) アカシ,AVK-C1)による硬さの測定を行った。 またX 線回折計（(株)リガク-Rint $2500 \mathrm{~V}-, \mathrm{CuK} \alpha, 50 \mathrm{kV}$, $150 \mathrm{~mA}) に よ り$ ，生成相の同定を行い，格子定数の測 定はシリコンを内部標準試料として、最小二乗法によって 求めた さらに焼結体の破面のSEM (JEOL JSM-

5310) 観察を行い微構造について検討した.

\section{3 実験結果および考察}

\subsection{X線回折}

$1700^{\circ} \mathrm{C}$ でホットプスしたC $\mathrm{C}_{1 \times \mathrm{x}} \mathrm{Mo}_{\mathrm{x}} \mathrm{B}_{2}$ 焼結体のX線 回折図形をFig. 1に示す. $1700^{\circ} \mathrm{C}$ において $=0.2 \sim$ 0.6 ま゙は $\mathrm{CrB}_{2}$ (六方晶系) 型固溶相だけの回折線

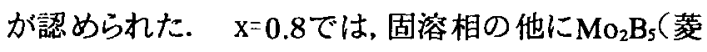
面体晶系 $)^{8)}$ 型相の回折線が認められた従って1700

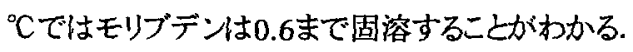

X線回折に妁同定された生成相をTable 1に示す. $x=0.2 \sim 0.6$, 焼結温度 $1600 \sim 1900^{\circ} \mathrm{C}$ 範囲で, 生成

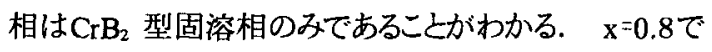
は1600 $1700^{\circ} \mathrm{C}$ 範囲で固溶相の他に第二相しして $\mathrm{Mo}_{2} \mathrm{~B}_{5}$ 型相が生成しており, $1900^{\circ} \mathrm{C}$ で $\mathrm{C}_{\mathrm{r}} \mathrm{B}_{2}$ 型固溶 相のみが生成していた。 これらのことから, $1400^{\circ} \mathrm{C} に$

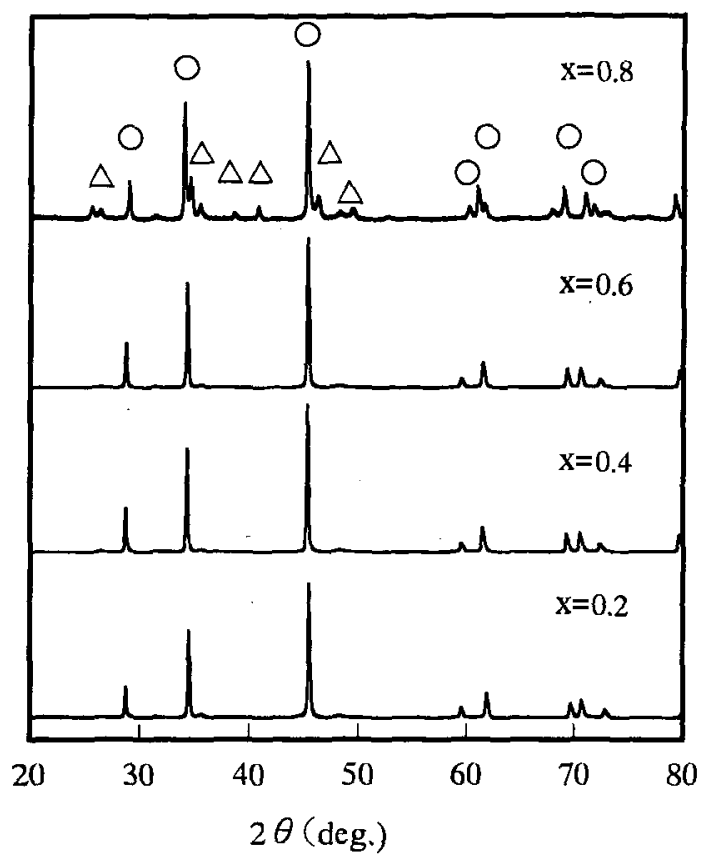

Fig.1 X-ray diffraction patterns of $\mathrm{Cr}_{1-\mathrm{X}} \mathrm{Mo}_{\mathrm{X}} \mathrm{B}_{2}$ ceramics hot-pressed at $1700^{\circ} \mathrm{C}$

$\mathrm{O}: \mathrm{CrB}_{2}$ (hexagonal) type solid solution

$\triangle: \mathrm{Mo}_{2} \mathrm{~B}_{5}$ (rhombohedral) type

Table 1 Identified phases by X-ray diffraction

\begin{tabular}{ccccc}
\hline $\begin{array}{c}\text { Mo } \\
\text { content }\end{array}$ & \multicolumn{4}{c}{ Temperature $\left({ }^{\circ} \mathrm{C}\right)$} \\
\hline $\mathrm{x}$ & 1600 & 1700 & 1800 & 1900 \\
\hline 0.2 & $\mathrm{CrB}_{2}$ & $\mathrm{CrB}_{2}$ & $\mathrm{CrB}_{2}$ & $\mathrm{CrB}_{2}$ \\
0.4 & $\mathrm{CrB}_{2}$ & $\mathrm{CrB}_{2}$ & $\mathrm{CrB}_{2}$ & $\mathrm{CrB}_{2}$ \\
0.6 & $\mathrm{CrB}_{2}$ & $\mathrm{CrB}_{2}$ & $\mathrm{CrB}_{2}$ & $\mathrm{CrB}_{2}$ \\
0.8 & $\mathrm{CrB}_{2}, \mathrm{MO}_{2} \mathrm{~B}_{5}$ & $\mathrm{CrB}_{2}, \mathrm{Mo}_{2} \mathrm{~B}_{5}$ & $\mathrm{CrB}, \mathrm{Mo}_{2} \mathrm{~B}_{5}$ & $\mathrm{CrB}_{2}$ \\
\hline
\end{tabular}

$\mathrm{CrB}_{2}: \mathrm{CrB}_{2}$ (hexagonal) type solid solution $\mathrm{Mo}_{2} \mathrm{~B}_{5}: \mathrm{Mo}_{2} \mathrm{~B}_{5}$ (rhombohedral) type

おけるCr-Mo-B三元系平衡状態図》゙ではモリブデンの 固溶限界は約0.5であるが, 焼結温度が高〈なるに従っ て, モリブデンの固溶限界は増加していることがかかる.

$\mathrm{Cr}_{1 \cdot \mathrm{x}} \mathrm{Mo}_{\mathrm{x}} \mathrm{B}_{2}$ 焼結体の格子定数 $(a, c)$ の変化とモ リブデン量の関係をFig. 2に, 格子体積とモリブデン量 の関係をFig. 3に示す. Fig. 2において格子定数 $a$ の 値は，文献值の $\mathrm{CrB}_{2}$ の $a$ 值 $(0.2973 \mathrm{~nm})^{9.10}$ 方ら $\mathrm{MoB}_{2}$ (六方晶系)の $a$ 值の $(0.3040 \mathrm{~nm})^{11)}$ の籁囲で連 


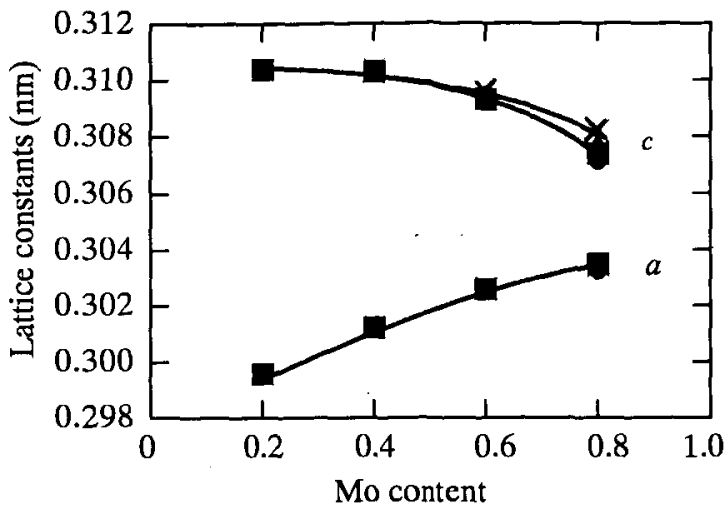

Fig.2 Relation between lattice constants of $\mathrm{Cr}_{1 \cdot \mathrm{X}} \mathrm{Mo}_{\mathrm{X}} \mathrm{B}_{2}$ and Mo content hot-pressing temp. $\mathbf{0}: 1600, \mathbf{\square}: 1700$, $\triangle: 1800, \times: 1900^{\circ} \mathrm{C}$

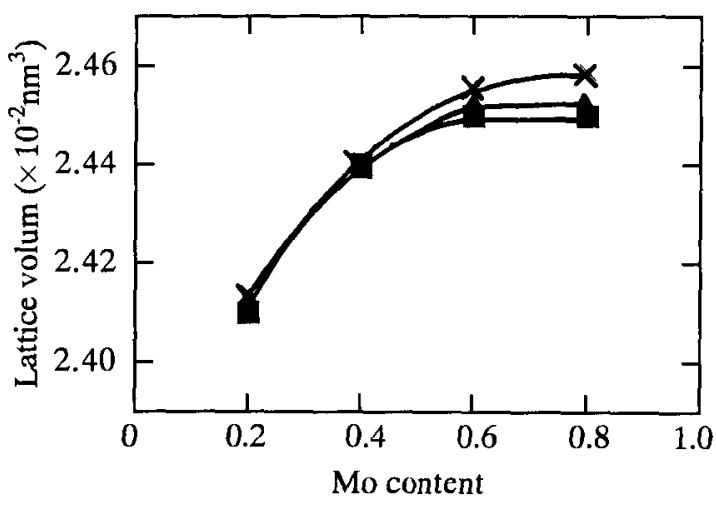

Fig. 3 Relation between lattice volume of the $\mathrm{Cr}_{1-\mathrm{X}} \mathrm{Mo}_{\mathrm{X}} \mathrm{B}_{2}$ ceramics and Mo content hot-pressing temp.

$\Delta: 1800, \times: 1900^{\circ} \mathrm{C}$

続的に変化し，モリブデン量が増加するに従って $\mathrm{MoB}_{2}$ の $a$ 值に近つく. 一方.格子定数の $c$ 值は, モリブデ ン量が少ないとき文献值のCrB 2 の $c$ 值(0.3071 $\mathrm{nm})^{9.10)}$ および $\mathrm{MoB}_{2} の c$ 值 $(0.3070 \mathrm{~nm})^{11)}$ 妁大きな值 を示し，モリブデン量が增加するに従って $\mathrm{CrB}_{2}$ および $\mathrm{MoB}_{2}$ の $c$ 值に近つく，また軸比 ( $\left.c / a\right)$ はてずれの 焼結温度でも、モリブデン量0.2〜0.8の籁囲でモリブデ ン量が增加するに従って, 1.036〜 1.013の間で変化し ている. これらの値は, 文献値の $\mathrm{CrB}_{2}$ の軸比 $c / a=$ 1.033 抽び $\mathrm{MoB}_{2}$ の軸比 $\mathrm{c} / a=1.001$ 坫僅汃大き い,従ってモリブデン量が増加すると $\mathrm{Cr}_{1 \cdot \times} \mathrm{Mo}_{\mathrm{x}} \mathrm{B}_{2}$ の六方 格子は $c$ 軸方向に僅かに伸びた結晶構造となってい

\section{ると推定される.}

Fig. 3から $\mathrm{Cr}_{1 \cdot \mathrm{x}} \mathrm{Mo}_{x} \mathrm{~B}_{2}$ 焼結体の格子体積はモリブデ ン量が增加するに従って増加したが, $\mathrm{x}=0.6$ 以下では 焼結温度に対する体積の変化はほとんど認められなかっ た $\mathrm{x}=0.6$ では焼結温度が高くなるに従って体積はわ ずかかに增加した $\mathrm{x}=0.6$ 以上では格子体積はほぼ 一定值を示すが, $1900^{\circ} \mathrm{C} 、 \mathrm{x}=0.8$ で体積はわずかに增 加し, モリブデンの固溶量がさらに増加することがわか る. 従って本研究の範囲ではモリブデンはX線的には， $1600 \sim 1800^{\circ} \mathrm{C}$ では約 $0.6,1900^{\circ} \mathrm{C} て ゙$ 約 0.8 まで固溶す る.

\section{2 焼結体の見かけ密度}

$\mathrm{Cr}_{1 \cdot \mathrm{x}} \mathrm{Mo}_{\mathrm{x}} \mathrm{B}_{2}$ 焼結体の見かけ密度と焼結温度の関

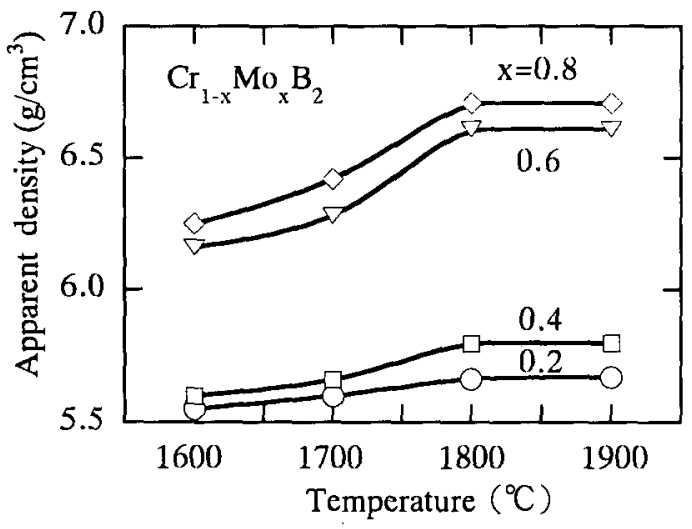

Fig.4 Relation between apparent density of $\mathrm{Cr}_{1-\mathrm{x}} \mathrm{Mo}_{\mathrm{x}} \mathrm{B}_{2}$ ceramics and hot-pressing temperature, as a function of Mo content.

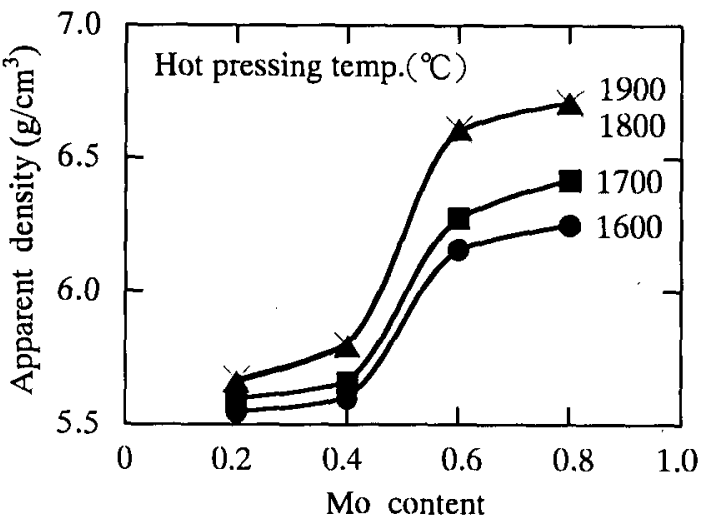

Fig.5 Relation between apparent density of $\mathrm{Cr}_{1-\mathrm{x}} \mathrm{Mo}_{\mathrm{x}} \mathrm{B}_{2}$ ceramics and Mo content, as a function of hot-pressing temperature. 


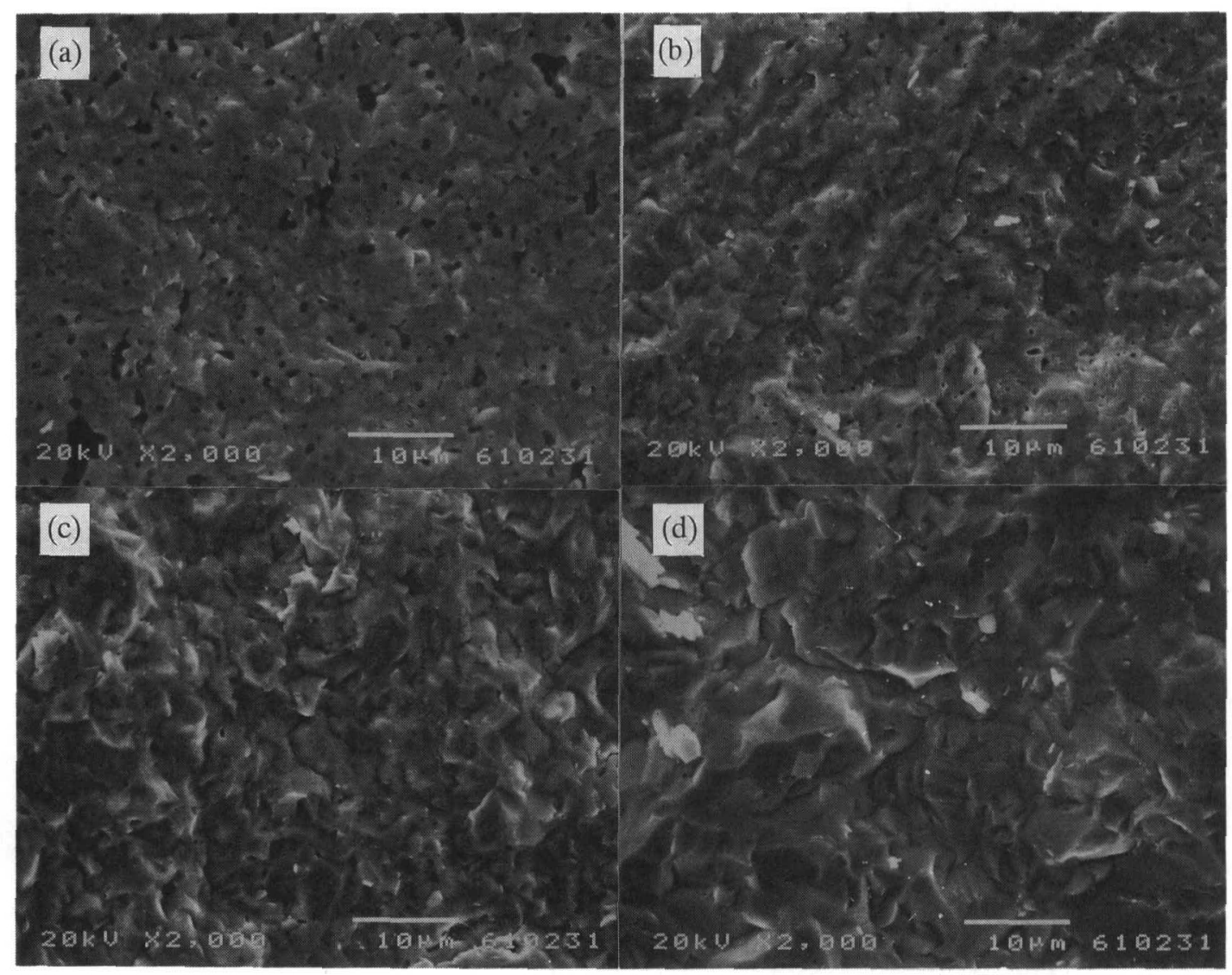

Photo.1 SEM photographs of $\mathrm{Cr}_{0.4} \mathrm{Mo}_{0.6} \mathrm{~B}_{2}$ creamics hot-pressed at (a) 1600, (b)1700, (c)1800, (d) $1900^{\circ} \mathrm{C}$.

係をFig.4に, $\mathrm{Cr}_{1-x} \mathrm{Mo}_{x} \mathrm{~B}_{2}$ 焼結体の見かけ密度とモリブ デン量の関係をFig. 5に示す. Fig. 4から,いずれの組 成についても焼結温度が高くなるに従って焼結体の見 かけ密度は高くなり, $1800^{\circ} \mathrm{C}$ 以上ではほぼ一定值を示 すことがわかる. Fig. 5から,いずれの焼結温度に対し てもモリブデン量の增加に従って焼結体の見かけ密度

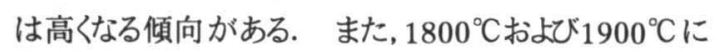
おける焼結体の見かけ密度はほぼ同じ值を示すことが わかる. そして,いずれの場合でも, モリブデン量0.6ま では焼結体の見かけ密度は大きく増加するが, モリブ デ量が0.6以上では焼結体の見かけ密度に顕著な 増加は認められない, 焼結体の見かけ密度は焼結 温度が $1800 \sim 1900^{\circ} \mathrm{C}$, モリブデン量が $0.6 \sim 0.8$ で最 大となった。

\section{3 SEM観察}

$1600 \sim 1900^{\circ} \mathrm{C}$ で焼結した $\mathrm{Cr}_{0.4} \mathrm{Mo}_{0.6} \mathrm{~B}_{2}$ 焼結体の破 面のSEM写真をPhoto.1に示す. $1600^{\circ} \mathrm{C}$ では焼結体 に気孔が多く認められ, 焼結体の密度は低いが, 焼結
温度が高くなるに従って気孔が少なくなり緻密化が進み 高密度になることがわかる. 一方焼結体の粒子は $1700^{\circ} \mathrm{C}$ までは微細な粒子であるが $1800^{\circ} \mathrm{C}$ 以上では粒 子が粗大化していることがわかる.

\section{4 硬さ}

$\mathrm{Cr}_{1-\mathrm{x}} \mathrm{Mo}_{\mathrm{x}} \mathrm{B}_{2}$ 焼結体の硬さと焼結温度の関係をFig. 6 に, $\mathrm{Cr}_{1 \times \mathrm{X}} \mathrm{Mo}_{\mathrm{x}} \mathrm{B}_{2}$ 焼結体の硬さとモリブデン量の関係を Fig. 7に示す. Fig.6において,いずれの組成において

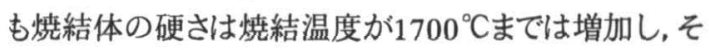
れ以上の温度では減少する傾向を示す. $1700^{\circ} \mathrm{C}$ では焼結温度が高くなるに従って焼結体が緻密化する ために硬さが増加し, $1700^{\circ} \mathrm{C}$ 以上の焼結温度では緻 密化は進むが, 焼結体の粒子が粗大化したために焼 結体の硬さは減少すると考えられる. Fig.7において, 焼結体の硬さはモリブデン量が増加するに従って増加 し, モリブデン量が 0.6 , 焼結温度が $1700^{\circ} \mathrm{C}$ で最大值約 $26.5 \mathrm{GPa}$ 示す. $\mathrm{Cr}_{1 \cdot \mathrm{x}} \mathrm{Mo}_{\mathrm{x}} \mathrm{B}_{2}$ 系において, $1600^{\circ} \mathrm{C}$ 以 上の温度ではモリプデンは $\mathrm{x}=0.6$ まで固溶し, 固溶量の 


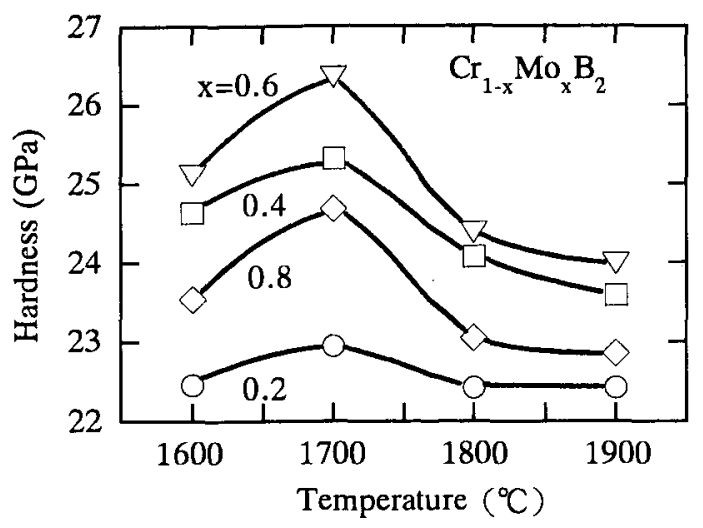

Fig.6 Relation between Vickers hardness of $\mathrm{Cr}_{1-\mathrm{x}} \mathrm{Mo}_{\mathrm{x}} \mathrm{B}_{2}$ ceramics and hot-pressing temperature, as a function of Mo content.

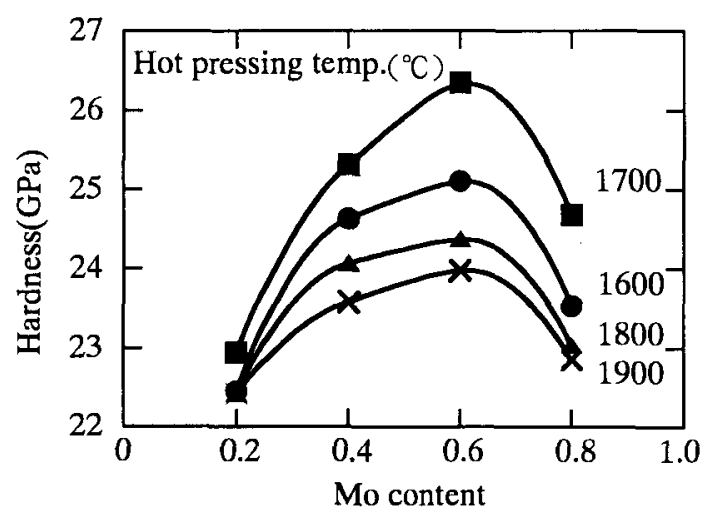

Fig.7 Relation between Vickers hardness of $\mathrm{Cr}_{1-\mathrm{x}} \mathrm{Mo}_{\mathrm{x}} \mathrm{B}_{2}$ ceramics and Mo content, as a function of hot-pressing temperature.

増加と共に固溶体の硬さが増加すると考えられる. またモリブデン量が $0.8 て ゙ は \mathrm{Cr}_{1 . \times} \mathrm{Mox}_{\mathrm{x}} \mathrm{B}_{2}$ 固溶相以外に 第二相が析出するために硬さが低下すると推定される。
4 結 言

$\mathrm{Cr}_{1-\mathrm{x}} \mathrm{Mox}_{\mathrm{x}} \mathrm{B}_{2}$ 系セラミックスのホットプスを行い次の結 果を得た $\mathrm{Cr}_{1 \cdot \times} \mathrm{Mo}_{\mathrm{X}} \mathrm{B}_{2}$ 系焼結体においてX線的にも

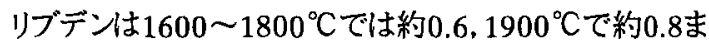
で固溶する． $\mathrm{Cr}_{1-\times} \mathrm{Mo}_{\mathrm{x}} \mathrm{B}_{2}$ 系焼結体の見かけ密度は モリブデン量が增加するに従って高くなり，焼結温度 $1800^{\circ} \mathrm{C}$ 以上でほぼ一定となった $\mathrm{Cr}_{1 \times \mathrm{X}} \mathrm{Mox}_{2}$ 系焼結 体の硬さはモリブデン量が0.6, 焼結温度 $1700^{\circ} \mathrm{C}$ しき 最大值約 $26.5 \mathrm{GPa}$ 示した

\section{文 献}

1) T. Lundström: Arkiv Kemi, (1969)227.

2) G. V. Samsonov,I.MVinitskii: 高融点化合物便覧， 日ソ通信社, (1977),p.302.

3) F. A. Shunk: Constitution of Binary Alloys (McGraw-Hill, New York, 1969) Suppll. 2,p.85.

4) S. Anderson, T. Lundström: Acta Chem. Scand., 22, (1968)3103.

5) C. N. Guy and A. A. Uraz: J. Less-Common Met., 48, (1976)199.

6) T. Lundström, in : Boron and Refractory Borides, ed.V.I. Matkovich (Springer, Berlin, 1977) p.351.

7) Кузьма Ю.Б.,Телеус В.С., КовалыкДА:Порошковая ме таллургия.,5,(1969)79.

8) Shigeru Okada, Tetuzo Atoda, Iwami Higashi, Yasuo Takahashi : J. Mat.Sci,, 22,(1987)2993.

9) 飯泉清賢, 吉川展和, 河野恵子, 岡田 繁, 久高克也, T. Lundström:日本化学会誌, 1992,1320 .

10) JCPDS 34-0369.

11) JCPDS 6-0682. 